\title{
The Effects of Greenness Exposure on Hypertension Incidence Among Chinese Oldest Old: A 10-Year Prospective Cohort Study
}

\section{Zhou Wensu}

Sun Yat-Sen University

Wang Wenjuan

Sun Yat-Sen University

\section{Zhou Fenfen}

Sun Yat-Sen University

\section{Chen Wen}

Sun Yat-Sen University

Li Ling ( $\square$ lingli@mail.sysu.edu.cn)

Sun Yat-Sen University https://orcid.org/0000-0003-3292-274X

\section{Research}

Keywords: greenness, China, hypertension, elderly, cohort study

Posted Date: December 22nd, 2021

DOI: https://doi.org/10.21203/rs.3.rs-1139608/v1

License: (9) This work is licensed under a Creative Commons Attribution 4.0 International License. Read Full License 


\section{Abstract \\ Background}

Present studies showed greenness affected hypertension incidence. While population-based epidemiologic studies are limited in the oldest-old population (aged 80+).

\section{Methods}

This was a 10-year prospective cohort study that included oldest old (80 years + ) from the Chinese Longitudinal Healthy Longevity Survey (CLHLS). Participants were free of hypertension at baseline (2008) and were followed up at 2011/2012, 2014, and 2018 waves. The 1-year average of the Normalized Difference Vegetation Index (NDVI) and Enhanced Vegetation Index (EVI) at 16-Day $500 \mathrm{~m}$ buffer before the year of hypertension event occurrence or last interview (for censoring) was estimated at 652 counties/districts units level of the participants resided and as exposure indicator. The non-linear association between greenness and hypertension incidence was performed by the Cox proportional hazards model with the penalized spline. The links between greenness and hypertension incidence were performed by the random-effects Cox proportional hazards model adjusted for potential confounding variables. We also examined the causal mediation effects of BMl, leisure activity, and $\mathrm{PM}_{2.5}$ on the association between greenness exposure and hypertension.

\section{Results}

Among 5432 participants, the incidence of hypertension was 7.25 (95\% Cl: 6.83 to 7.67$)$ per 100 personyears. We found a non-liner association existed between greenness exposure and hypertension risk. In the fully adjusted model, the third tertile of NDVI value presenting protective effects on hypertension incidence compared with the first tertile (hazard ratios (HRs): $0.51 ; 95 \%$ confidence interval: 0.40-0.64). The third tertile of EVI value had a significant protective effect on hypertension incidence, compared with participants in the first tertile (HRs:0.44, 95\%Cl: 0.34-0.55). The effect of greenness exposure on hypertension was more pronounced in participants living in central/western China. We observed there were $41.63 \%$ and $17.01 \%$ of the association between NDVI/EVI exposure and hypertension was mediated by $\mathrm{PM}_{2.5}$, respectively.

\section{Conclusions}

Greenness could decrease approximate $50 \%$ risk induced by hypertension among oldest-old people, that is, expanding greenness is a recommended approach to hypertension prevention for the them. In particular, implementing plans to expanding green space construction in central/western China is needed. It is also emphasized the the importance of improve air quality when greenness exposure is existing. 


\section{Background}

Greenness, comprised of vegetation and closely connected with natural elements [1], which was a heatedly discussed environmental indicator in medical and health sciences field [2]. Increasing number of studies confirmed that greenness was very benefit to cardiovascular health. From the view of biologically reasons, greenness can able to thwarting environmental hazards' attack then reduce the damage to cardiocerebral vascular system caused by air pollutants, noise et al; spend time to greenness can relieve mental stress; exposure to greenness help to prevent overweight and obesity also [3].

Currently, the ensuing rapid trends of the aging and expanding oldest old population size (i.e., those aged $80+$ years) has resulted in large disease burdens of cardiovascular diseases (CVDs) [4, 5]. Hypertension, which is a well-known important contributor to CVDs, not only as the first leading preventable risk factor for CVDs but also has the highest prevalence among oldest old $[2,6]$. Nowadays, make effort to prevent the onset of hypertension is critical to reduce the diesase burden of CVDs and promote healthy aging.

Previous studies have revealed a negative association between greenness and hypertension risk [7-10], despite it, a number of questions remain unanswered. First, number of studies investigated the association between greenness and hypertension in older adults, but the result findings were mixed. For instance, prior two surveys found there were not significant association between greenness exposure and blood pressure in the older adults $[11,12]$. Second, there are inadequate studies in the literature involving elderly aged over 80 years, although the prevalence of hypertension in the oldest-old elderly was quite high and they were more vulnerable to environmental risk factors due to organ function decline [13]. Third, published studies reported there was a modification effect of the relationship between greenness and blood pressure varied by elderly's age. Some studies proposed this protective effects were stronger in younger age elderly but others were not, due to the rare sample for oldest-old people, this modification effect of age was not fully understand $[9,10,14]$. In addition, previous cross-sectional study designs have dominated the literature $[7,15,16]$. However, hypertension's prevalence is usually chronic progression and relate to long-term greenness exposure. There were rare data on the prospective effects of greenness exposure on hypertension incidence, implying a restricted causal inference ability when generalizing results. Furthermore, there were lots of published literature characterized by local areas and mostly with small sample sizes that influenced the sample representativeness $[17,18]$.

Numerous studies have explored air pollution, body mass index (BMI), and physical activity may be the mediators in the mechanism association between greenness and health $[7,19]$, but little is known in oldest-old elderly and study characterised by survival outcome. Meanwhile, some surveys emphasized that greenness could promote elder's leisure activity, thereby reducing the risk of adverse health outcomes $[20,21]$. To date, however, this potential pathway between greenness and hypertension whether mediated by leisure activity was unclear.

Importantly, the recommendations in the guideline for the prevention of geratic hypertension was updated every few years relying on newer evidences for the influence of risk factors on hypertension. However, far less attention has been paid to environmental risk in practice guideline for the elderly. Although 
environmental factors omnipersent nature and surely have clinically meaningful effects on hypertension [22], probably due to limited evidences for population-based sample and causal inference. As societies are progressively aging and continuous increment in geratic hypertension prevalence, a deeper understanding for the association between greenness and hypertension in specific older adults is expected to be reported.

Therefore, the objective of the study was to examine the association between greenness exposure and hypertension incidence based on a 10-year prospective cohort study of elderly aged $80+$ in China. We also aimed to respond to whether the mediation effects of $\mathrm{BMI}$, air pollution, and leisure activity exist between greenness and hypertension incidence.

\section{Method}

\section{Study design and population}

The participants were derived from a public open database - CLHLS, which was a national investigation recruited elderly aged over 65 years and older from 23 of 31 province/ autonomous region / municipality in mainland China. Since the first investigation (1998), the CLHLS has conducted eighth investigations until 2018 wave. Detailed introduction of CLHLS was published elsewhere [23].

To protect the participants' privacy, the home address information was removed in this open-public database. Thus, we selected fifth (2008) wave as baseline due to the information of residence units (at counties/districts level) of the participants resided were available from community investigation questionnaire [24]. At baseline, participants were excluded if they were aged under 80 years, missing on relevant information (demographic characteristics, blood pressure and exposure assessment), and had hypertension (systolic blood pressure (SBP) $\geq 140 \mathrm{~mm} \mathrm{Hg} 140$ or diastolic blood pressure (DBP) $\geq 90 \mathrm{~mm}$

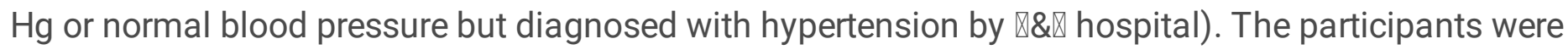
followed up in sixth (2011/2012), seventh (2014), and eighth (2018) investigation. The detailed flow chart of current study is shown in Figure 1. Finally, we focused on 5253 participants who older than 80 years old with available information and were followed up in the study. Only $1.3 \%$ of participants changed their residence (county/district) in our study. Thus, the sample population was highly stationary because they were less likely to move to another address with advanced age and hukou household registration system [25]. We also performed sensitivity analysis by excluding participants changed residence (Table S4).

The Research Ethics Committees of Peking University and Duke University granted approval for the Protection of Human Subjects for the Chinese Longitudinal Healthy Longevity Survey, including collection of the data used for present study. The survey respondents gave informed consent before participation.

The duration of follow-up was from the date participants enrolled in the project to the date of hypertension event occurrence or death or end of follow-up, whichever occurs first. Person years were calculated by precise method (days/365). The follow-up ended when hypertension event occurrence or 
discontinued their participation (i.e. censoring including death, lost follow-up and not identified as hypertension).

\section{Hypertension assessment}

As a part of CLHLS, in baseline and each interview, the participants' SBP and DBP were measured between five minutes rest interval by mercurial sphygmomanometer and performed by trained physician. Through two times repeated measurement (between five or longer rest interval) of blood pressure, the average value of SBP and DBP were calculated. Specifically, for bedbound participants, blood pressure measurements were obtained in a recumbent position. Simultaneously, participants were also asked to respond to the following question: "Are you suffering from hypertension and diagnosed by hospital or not ?". According to guideline, in our study, hypertension was defined as SBP $\geq 140 \mathrm{~mm} \mathrm{Hg} 140$ or DBP $\geq 90$ $\mathrm{mm} \mathrm{Hg}$ or normal blood pressure value but self-reported be diagnosed with hypertension by $\mathbb{\otimes} \otimes$ hospital. Similar study used same definition of hypertension basing on the CLHLS database was published previously [26].

\section{Greenness assessment}

The Normalized Difference Vegetation Index (NDVI) and enhanced vegetation index (EVI) sourced from the Moderate Resolution Imaging Spectroradiometer (MODIS) Terra were used as estimation of greenness. They were recorded per 16-day at a spatial resolution of 250, 500, and $1000 \mathrm{~m}$, respectively. The two satellite-derived vegetation indices reflected vegetation of ground with range from -1 to 1 . In general, NDVI of 0.1 or below reflected barren areas of rock, sand or snow; NDVI between 0.2 to 0.4 reflected shrub and grassland. The higher value of NDVI/EVI, the denser greenness. Referring to previous study [27], based on NDVI/EVI free of cloud of 16-day recorded for $500 \mathrm{~m}$ buffer, the 1-year average of $\mathrm{NDVI} / \mathrm{EVI}$ value before the year of last interview (only for censoring) or hypertension event occurrence was treated as greenness exposure in our study. Because this window period had greatest impacts on hypertension incidence (Table S1). In particular, due to the individual privacy protection, exact address of residence was unavailable, thus, the exposure was assessed at a community-based unit level (districts/counties) the elderly resided. Those cloud-free of NDVI/EVI value were available downloaded from the Google Earth Engine (https://developers.google.cn/earth-engine) and they were extracted through ArcGIS 10.6 (ESRI, Redlands, CA, USA) in this study. Specific, the one year average of NDVI/ EVI before event at a spatial resolution of 16-day with $250 \mathrm{~m}$ and $1000 \mathrm{~m}$ buffer were used to sensitivity analyses.

\section{Potential confounding variables and mediators}

Some of the baseline characteristics were used to control confounding in the study. Including: age, gender (female, male), residence (rural/town, urban), geographical regions (eastern China, central/western China), pension (yes, no), living arrangements (with family member, nursing home/alone), education attainment (uneducated, educated), marital status (married/living together, widowed, and /single/divorced/separated), smoking status at the present (yes, no), drinking status at the 
present (yes, no), exercising habit at the present (yes, no), self-reported heart disease (yes, no), selfreported diabetes (yes, no), and ADL (Activities of Daily Living). In particular, ADL was evaluated by selfreport regarding physical ability in basic self-care tasks, which was consist with six items including bathing, dressing, eating, toileting, continence, and transferring $[28,29]$. If an participant is able to perform an activity, he/she gets score 1 , and if he/she is limited to do and unable to do so, will get score 2 and 3, respectively. The more scores of the individual, indicates poor ADL ability.

According to prior studies, we selected contemporaneous $\mathrm{PM}_{2.5}$ concentration, $\mathrm{BMI}$ index, and leisure activity at the baseline as mediators in the analysis. Among them, baseline $\mathrm{PM}_{2.5}$ concentration in 652 units of the subjects resided was collected from a public open database built by Atmospheric Composition Analysis Group from University of Washington [30]. Researchers used satellite combining Aerosol Optical Depth (AOD) retrievals from multiple satellite products (MISR, MODIS Dark Target, MODIS and SeaWiFS Deep Blue, and MODIS MAIAC) to report ground-level of $\mathrm{PM}_{2.5}$ concentration with $1.1 \times 1.1$ $\mathrm{km}$ resolution.

Leisure activity was collected from individual questionnaire included following activity: housework ; personal outdoor activities; garden work; read newspapers/books; raising domestic animals; playing cards and/or mahjongg; watching television and/or listening to the radio; organized activities. The checklist was ratings using a 5-point Likert scale. Each opinion was scored on a scale of 1 (never), 2 (not every month, but sometimes), 3 (not every week, but at least once a month), 4 (not every day, but at least once a week), or 5 (almost every day). As recommend, we calculated total points and divided by the full score to measure leisure activity (range $=0-1)$ [31].

\section{Statistic analysis}

Descriptive statistic analysis was performed firstly. The continuous variables with normal distribution were reported as mean \pm standard deviation (SD). Median (interquartile range) was presented for variables with non-normal distribution. The categorical variables were reported as number and percentage.

The Cox proportional hazards regression models of penalized spline with different degree of freedom $(2 / 3 / 4)$ was conducted to examine the potential non-liner association between greenness and hypertension incidence basing on minimum AIC (Akechi information criterion) value.

Given the set clustering of the study designs, to evaluate the associations of greenness exposure with the occurrence of hypertension, the random-effects Cox proportional hazards regression models were performed. In this analysis, the 652 units was set as a random effects term in the models. We first explored the links between 0.1-unit increment in greenness and hypertension. Furthermore, due to the nonliner association between greenness exposure and hypertension (Figure S2 and S3). We categorized $\mathrm{NDVI} / \mathrm{EVI}$ into three categories basing on tertile: first tertile (lowest and as reference, $\leq P_{50}$ ), second tertile $\left(P_{50}-P_{75}\right)$, and third tertile (highest, $\left.>P_{75}\right)$. The crude model only included NDVI/ EVI (model 1). The model 
2 was developed by further adjusting for age, gender, residence, geographical regions, pension, living arrangements, education attainment, marital status, smoking status at the present, drinking status at the present, exercising habit at the present, self-reported heart disease, self-reported diabetes, $\mathrm{PM}_{2.5}$, leisure activity, and BMI (model 2). We also built trend analysis between greenness exposure and hypertension risk by setting NDVI/EVI tertile as continuous variables in the models. For a robustness check, the EVI/ NDVI in 250 and $1000 \mathrm{~m}$ buffer was used to test the sensitivity of our results. In addition, we excluded the participants who were self-reported had diabetes/heart disease/dead during follow-up to verify the effects of residential greenness exposure and hypertension incidence (Table S4). Subgroup and interaction effects analysis were performed to identify vulnerable population affected by greenness exposure. The interaction effects of NDVI/ EVI and four variables on hypertension incidence by perform a cross-product term.

We conducted a one-mediator model to explore the mediation effects of each 0.1-unit increment in greenness exposure and hypertension incidence mediated by mediators ( $\mathrm{PM}_{2.5}$, leisure activity, and $\left.\mathrm{BMI}\right)$ based on the survival outcomes. The detailed theoretical foundation, $\mathrm{R}$ codes, and calculation principle were published in the study of Huang and Yang [32]. In the model, the product of the two effects in the hazard ratio scale: $\mathrm{TE}_{\mathrm{HR}}=\mathrm{DE}_{\mathrm{HR}} \times \mathrm{IE}_{\mathrm{HR}}$, or equivalently, $\mathrm{TE}_{\text {log } \mathrm{HR}}=\mathrm{DE} \mathrm{E}_{\text {log HR}}+\mathrm{IE}_{\text {log } \mathrm{HR}}$. The mediation proportion was calculated as the natural log of indirect effect divided the total effect and expressed as a percentage [33].

Effect estimates are showed as hazard ratio (HR) and corresponding $95 \%$ confidence intervals (Cls). The map of China was derived from National Geomatics Center of China (http://www.ngcc.cn/ngcc/), the statistics map was generated by ArcGIS Geospatial Analyst module v10.6 (ESRI, Redlands, CA, USA). All of analysis were 2-sided level of significance was set at 0.05 . All of analysis were performed using $R$ studio (R 4.0.5, R Foundation for Statistical Computing, Vienna, Austria).

\section{Result}

The demographic characteristics of the participants are given in Table 1. Among 5432 participants, a total of 1048 new cases of hypertension were observed, including 14454.64 person-years of follow-up, with an incidence of 7.25 (95\% Cl: 6.83 to 7.67$)$ per 100 person-years. The mean age of the subjects was 93.7 years $(S D=7.16)$ with range from 81 to 116 years. Over half of the participants $(60.9 \%)$ were females. Only $28.4 \%$ of the elderly were educated. $80.9 \%$ of them living in town/rural areas, and most of them were widowed (81.7\%), living with family members (83.4\%). Most of the participants had not pension. The mean ADL value of the elderly was $7.25(S D=2.61)$ (Table 1). 
Table 1

Demographic characteristics of the participants at baseline $(\mathrm{N}=5253)$

\begin{tabular}{|c|c|c|}
\hline Variables & Overall & $\mathrm{n}(\%) /$ mean $\pm \mathrm{SD}$ \\
\hline Age & & $93.7(7.16)$ \\
\hline \multicolumn{3}{|l|}{ Gender } \\
\hline & Female & $3201(60.9)$ \\
\hline & Male & $2052(39.1)$ \\
\hline \multicolumn{3}{|c|}{ Education attainment } \\
\hline & Uneducated & $3763(71.6)$ \\
\hline & Educated & $1490(28.4)$ \\
\hline \multicolumn{3}{|l|}{ Pension } \\
\hline & No & $4525(86.1)$ \\
\hline & Yes & 728 (13.9) \\
\hline \multicolumn{3}{|l|}{ Residence } \\
\hline & Rural/Town & $4251(80.9)$ \\
\hline & Urban & $1002(19.1)$ \\
\hline \multicolumn{3}{|c|}{ Living arrangement } \\
\hline & Nursing home/alone & $871(16.6)$ \\
\hline & Living with family members & $4382(83.4)$ \\
\hline \multicolumn{3}{|l|}{ Region } \\
\hline & Central/western China & $3208(61.1)$ \\
\hline & Eastern China & 2045 (38.9) \\
\hline \multicolumn{3}{|c|}{ Marital status } \\
\hline & Single/divorced/separated & $57(1.1)$ \\
\hline & Window & $4294(81.7)$ \\
\hline & Married/living together & $902(17.2)$ \\
\hline \multicolumn{3}{|c|}{ Smoking status at the present } \\
\hline & No & $4517(86.0)$ \\
\hline & Yes & $736(14.0)$ \\
\hline
\end{tabular}




\begin{tabular}{|lll|}
\hline Variables & Overall & $\mathrm{n}(\%) /$ mean \pm SD \\
\hline & No & $4409(83.9)$ \\
\hline Exercising habit at the present & Yes & $844(16.1)$ \\
\hline & No & $4089(77.8)$ \\
\hline Self-reported diabetes & Yes & $1164(22.2)$ \\
\hline & No & $5184(98.7)$ \\
\hline Self-reported heart disease & Yes & $69.0(1.3)$ \\
& No & \\
\hline ADL & Yes & $4988(95.0)$ \\
BMI & & $265(5.0)$ \\
\hline Leisure activity & & $6.0(6.0-7.0)$ \\
\hline
\end{tabular}

The spatial distribution of NDVI/EVI value at baseline in 652 units among 5253 oldest-old elderly of China is presented in Figure 1. We also presented spatial distribution of NDVI/EVI value at baseline across China (Figure S1). The mean NDVI and EVI of the units were $0.46(S D=0.11)$ and $0.29(S D=0.07)$, respectively. The participants exposure to $\mathrm{PM}_{2.5}$ with mean concentration was $53.93(\mathrm{SD}=16.00)$ (Table 2).

Table 2

Descriptive statistics analysis for greenness exposure and air pollutant

\begin{tabular}{|lllllllll|}
\hline Variables & Mean & SD & Min & \multicolumn{2}{l}{ Quantiles } & & Max & Interquartile range \\
\cline { 5 - 7 } & & & & $\mathbf{P}_{\mathbf{2 5}}$ & $\mathbf{P}_{\mathbf{5 0}}$ & $\mathbf{P}_{\mathbf{7 5}}$ & & \\
\hline $\mathrm{EVI}$ & 0.29 & 0.07 & 0.05 & 0.25 & 0.30 & 0.34 & 0.44 & 0.19 \\
\hline $\mathrm{NDVI}$ & 0.46 & 0.11 & 0.09 & 0.39 & 0.48 & 0.54 & 0.69 & 0.15 \\
\hline $\mathrm{PM}_{2.5}$ & 53.93 & 16.00 & 9.44 & 42.78 & 51.81 & 68.02 & 95.60 & 25.24 \\
\hline
\end{tabular}


Table 3 reported the results of random-effects Cox proportion hazard models for the association between greenness exposure and hypertension incidence. The NDVI and EVI value were strongly correlated with hypertension incidence in the crude model. In the fully adjusted model, referring to the 1 st tertile of NDVI value, the HRs for the second tertile and third tertile were 0.86 (95\% Cl: $0.70-1.05)$ and 0.51 (95\% Cl: $0.40-$ $0.64)$, respectively. We found the third tertile of EVI value was significant associated with hypertension incidence after controlling for confounding variables $(\mathrm{HR}=0.44,95 \% \mathrm{Cl}: 0.34-0.55)$. Each 0.1 -unit increase in NDVI/EVI was associated with lower hypertension risk ( $\mathrm{HR}=0.80,95 \% \mathrm{Cl}: 0.74-0.87$ for NDVl; $\mathrm{HR}=0.68$, 95\% Cl: $0.60-0.77$ for $\mathrm{EVI})$. We performed tests for linear trend by entering the tertile of $\mathrm{NDVI} / \mathrm{EVI}$ as a continuous variable in the models, and these associations did reach statistical significance $(P$ for trend $<0.05$ ) (Table 3). When examining the association between NDVI/EVI value in the $250 \mathrm{~m}$ and $1000 \mathrm{~m}$ buffer and hypertension occurrence, this association remained significant in sensitivity analysis (Table S2). Besides, the results were not substantially changed after excluding participants self-reported had diabetes, changed residence, death during follow up and heart disease (Table S3). 
Table 3

The association between greenness exposure and hypertension incidence among 5453 oldest old population

\begin{tabular}{|c|c|c|c|c|c|}
\hline Index & Groups & Model 1 & Model 2 & $\begin{array}{l}\text { P for } \\
\text { trend }\end{array}$ & $\begin{array}{l}\text { Increment in each } 0.1 \text { unit increase } \\
\text { in greenness exposure }{ }^{a}\end{array}$ \\
\hline \multicolumn{6}{|l|}{ NDVI } \\
\hline & $\begin{array}{l}\text { Tertile } \\
1\end{array}$ & 1 & 1 & $<0.001$ & $0.80(0.74-0.87)$ \\
\hline & $\begin{array}{l}\text { Tertile } \\
2\end{array}$ & $\begin{array}{l}0.99(0.81- \\
1.20)\end{array}$ & $\begin{array}{l}0.86(0.70- \\
1.05)\end{array}$ & & \\
\hline & $\begin{array}{l}\text { Tertile } \\
3\end{array}$ & $\begin{array}{l}0.68(0.53- \\
0.84)\end{array}$ & $\begin{array}{l}0.51(0.40- \\
0.64)\end{array}$ & & \\
\hline \multicolumn{6}{|l|}{ EVI } \\
\hline & $\begin{array}{l}\text { Tertile } \\
1\end{array}$ & 1 & 1 & $<0.001$ & $0.68(0.60-0.77)$ \\
\hline & $\begin{array}{l}\text { Tertile } \\
2\end{array}$ & $\begin{array}{l}0.97(0.80- \\
1.17)\end{array}$ & $\begin{array}{l}0.85 \\
(0.70- \\
1.03)\end{array}$ & & \\
\hline & $\begin{array}{l}\text { Tertile } \\
3\end{array}$ & $\begin{array}{l}0.52(0.41- \\
0.66)\end{array}$ & $\begin{array}{l}0.44(0.34- \\
0.55)\end{array}$ & & \\
\hline \multicolumn{6}{|l|}{ Note: } \\
\hline \multicolumn{6}{|c|}{ Model 1: Crude model only included NDVI/EVI. } \\
\hline \multicolumn{6}{|c|}{$\begin{array}{l}\text { Model 2: Crude model + further adjusted for age, living arrangement, PM2.5, regions, ADL, residence, } \\
\text { gender, smoking, drinking, exercising, pension, martial status, education attainment, self-reported } \\
\text { diabetes, self-reported heart disease, and BMI. }\end{array}$} \\
\hline
\end{tabular}


Table 4

Subgroup analysis for the association between NDVI value and hypertension incidence

\begin{tabular}{|c|c|c|c|c|}
\hline \multirow[t]{2}{*}{ Covariates } & $\begin{array}{l}\text { 1st } \\
\text { tertiles }\end{array}$ & 2nd tertiles & 3nd tertiles & \multirow[t]{2}{*}{$\begin{array}{l}P \text { value for } \\
\text { interaction }\end{array}$} \\
\hline & $\begin{array}{l}\mathrm{HR} \\
(95 \% \mathrm{Cl})\end{array}$ & HR (95\%Cl) & HR $(95 \% \mathrm{Cl})$ & \\
\hline \multicolumn{5}{|l|}{ Regions } \\
\hline Central/western & 1 & $\begin{array}{l}0.82(0.64- \\
1.05)\end{array}$ & $\begin{array}{l}0.35(0.25- \\
0.47)\end{array}$ & 0.002 \\
\hline Eastern & 1 & $\begin{array}{l}0.60(0.38- \\
0.94)\end{array}$ & $\begin{array}{l}0.92(0.64- \\
1.32)\end{array}$ & \\
\hline \multicolumn{5}{|l|}{ Gender } \\
\hline Male & 1 & $\begin{array}{l}0.91(0.68- \\
1.24)\end{array}$ & $\begin{array}{l}0.73(0.53- \\
1.01)\end{array}$ & 0.084 \\
\hline Female & 1 & $\begin{array}{l}0.89(0.69- \\
1.14)\end{array}$ & $\begin{array}{l}0.50(0.38- \\
0.67)\end{array}$ & \\
\hline \multicolumn{5}{|l|}{ Residence } \\
\hline Rural/Town & 1 & $\begin{array}{l}0.87(0.71- \\
1.08)\end{array}$ & $\begin{array}{l}0.50(0.40- \\
0.64)\end{array}$ & 0.130 \\
\hline Urban & 1 & $\begin{array}{l}0.60(0.26- \\
1.39)\end{array}$ & $\begin{array}{l}0.35(0.08- \\
1.59)\end{array}$ & \\
\hline $\begin{array}{l}\text { Smoking status at the } \\
\text { present }\end{array}$ & & & & 0.230 \\
\hline Yes & 1 & $\begin{array}{l}0.76(0.46- \\
1.25)\end{array}$ & $\begin{array}{l}0.73(0.42- \\
1.24)\end{array}$ & \\
\hline No & 1 & $\begin{array}{l}0.89(0.71- \\
1.11)\end{array}$ & $\begin{array}{l}0.50(0.39- \\
0.64)\end{array}$ & \\
\hline $\begin{array}{l}\text { Drinking status at the } \\
\text { present }\end{array}$ & & & & 0.570 \\
\hline Yes & 1 & $\begin{array}{l}0.97(0.64- \\
1.46)\end{array}$ & $\begin{array}{l}0.57(0.35- \\
0.90)\end{array}$ & \\
\hline No & 1 & $\begin{array}{l}0.87(0.70- \\
1.09)\end{array}$ & $\begin{array}{l}0.54(0.42- \\
0.69)\end{array}$ & \\
\hline
\end{tabular}

Note:

The associations were adjusted by age, living arrangement, $P M_{2.5}$, regions, $A D L$, residence, gender, smoking, drinking, exercising, pension, martial status, leisure activity, education attainment, selfreported diabetes, self-reported heart disease, and BMI. 


\begin{tabular}{|c|c|c|c|c|}
\hline \multirow[t]{2}{*}{ Covariates } & $\begin{array}{l}1 \text { st } \\
\text { tertiles }\end{array}$ & 2nd tertiles & 3nd tertiles & \multirow[t]{2}{*}{$\begin{array}{l}P \text { value for } \\
\text { interaction }\end{array}$} \\
\hline & $\begin{array}{l}\text { HR } \\
(95 \% \mathrm{Cl})\end{array}$ & $\mathrm{HR}(95 \% \mathrm{Cl})$ & $\mathrm{HR}(95 \% \mathrm{Cl})$ & \\
\hline \multicolumn{4}{|l|}{$\begin{array}{l}\text { Exercising habit at the } \\
\text { present }\end{array}$} & \multirow[t]{2}{*}{0.610} \\
\hline Yes & 1 & $\begin{array}{l}0.85(0.59- \\
1.24)\end{array}$ & $\begin{array}{l}0.69(0.48- \\
1.00)\end{array}$ & \\
\hline No & 1 & $\begin{array}{l}0.91(0.72- \\
1.14)\end{array}$ & \multicolumn{2}{|l|}{$\begin{array}{l}0.52(0.40- \\
0.68)\end{array}$} \\
\hline \multicolumn{5}{|l|}{ Note: } \\
\hline \multicolumn{5}{|c|}{$\begin{array}{l}\text { The associations were adjusted by age, living arrangement, } \mathrm{PM}_{2.5} \text {, regions, } \mathrm{ADL} \text {, residence, gender, } \\
\text { smoking, drinking, exercising, pension, martial status, leisure activity, education attainment, self- } \\
\text { reported diabetes, self-reported heart disease, and BMI. }\end{array}$} \\
\hline
\end{tabular}


Table 5

Subgroup analysis for the association between EVI value and hypertension incidence

\begin{tabular}{lllll} 
Covariates & $\begin{array}{l}1 \text { st } \\
\text { tertiles }\end{array}$ & 2nd tertiles & 3nd tertiles & $\begin{array}{l}\text { P value for } \\
\text { interaction }\end{array}$ \\
\cline { 2 - 4 } & $\begin{array}{l}\mathrm{HR} \\
(95 \% \mathrm{Cl})\end{array}$ & $\mathrm{HR}(95 \% \mathrm{Cl})$ & $\mathrm{HR}(95 \% \mathrm{Cl})$ & \\
& & &
\end{tabular}

Regions

Central/western

1

$1.03(0.81-$

1.32)

$0.47(0.35-$

$0.63)$

0.330

Eastern

1

$0.60(0.43-$

0.83 )

0.44(0.29-

$0.67)$

Gender

$\begin{array}{llll}\text { Male } & 1 & 1.00(0.76- & \mathbf{0 . 5 5 ( 0 . 3 9 -} \\ & & 1.32) & \mathbf{0 . 7 7 )} \\ \text { Female } & 1 & 0.84(0.66- & \mathbf{0 . 4 9 ( 0 . 3 7 -} \\ & & 1.06) & \mathbf{0 . 6 5 )}\end{array}$

Residence

$\begin{array}{lllll}\text { Rural/Town } & 1 & 0.84(0.69- & \mathbf{0 . 4 1 ( 0 . 3 2 -} & 0.160 \\ & & 1.02) & \mathbf{0 . 5 3}) & \\ \text { Urban } & 1 & 0.64(0.21- & 0.77(0.31- & \\ & & 1.90) & 1.95) & \end{array}$

Smoking status at the present

$\begin{array}{lllll}\text { Yes } & 1 & 0.84(0.54- & \mathbf{0 . 4 3 ( 0 . 2 4 -} & 0.410 \\ & & 1.31) & \mathbf{0 . 7 6 )} & \\ \text { No } & 1 & 0.88(0.72- & \mathbf{0 . 4 6 ( 0 . 3 6 -} & \\ & & 1.09) & \mathbf{0 . 5 9})\end{array}$

Drinking status at the present

\begin{tabular}{|c|c|}
\hline Yes & 1 \\
\hline
\end{tabular}

No

1

$\begin{array}{ll}0.89(0.72- & \mathbf{0 . 4 9}(0.38- \\ 1.10) & \mathbf{0 . 6 4 )}\end{array}$

Note:

The associations were adjusted by age, living arrangement, PM2.5, regions, ADL, residence, gender, smoking, drinking, exercising, pension, martial status, leisure activity, education attainment, selfreported diabetes, self-reported heart disease, and BMI. 


\begin{tabular}{|c|c|c|c|c|}
\hline \multirow[t]{2}{*}{ Covariates } & $\begin{array}{l}1 \text { st } \\
\text { tertiles }\end{array}$ & 2nd tertiles & 3nd tertiles & \multirow[t]{2}{*}{$\begin{array}{l}P \text { value for } \\
\text { interaction }\end{array}$} \\
\hline & $\begin{array}{l}\mathrm{HR} \\
(95 \% \mathrm{Cl})\end{array}$ & $\mathrm{HR}(95 \% \mathrm{Cl})$ & HR (95\%Cl) & \\
\hline \multicolumn{5}{|c|}{$\begin{array}{l}\text { Exercising habit at the } \\
\text { present }\end{array}$} \\
\hline Yes & 1 & $\begin{array}{l}0.82(0.59- \\
1.15)\end{array}$ & $\begin{array}{l}0.65(0.45- \\
0.94)\end{array}$ & 0.730 \\
\hline No & 1 & $\begin{array}{l}0.94(0.75- \\
1.17)\end{array}$ & $\begin{array}{l}0.44(0.34- \\
0.58)\end{array}$ & \\
\hline \multicolumn{5}{|l|}{ Note: } \\
\hline \multicolumn{5}{|c|}{$\begin{array}{l}\text { The associations were adjusted by age, living arrangement, PM2.5, regions, ADL, residence, gender, } \\
\text { smoking, drinking, exercising, pension, martial status, leisure activity, education attainment, self- } \\
\text { reported diabetes, self-reported heart disease, and BMI. }\end{array}$} \\
\hline
\end{tabular}

The figure 3 and 4 report the subgroup analysis results of the study. Only a significant region $\times$ greenness interaction term for hypertension was detected $(p<0.05)$. The population from central/western regions were more vulnerable to greenness exposure than others reside in regions $(\mathrm{HR}=0.35,95 \% \mathrm{Cl}$ : $0.25-0.47)$.

After adjusted for confounding variables, in our study, we found the association between greenness and hypertension was partly mediated by air pollution. As presented in Figure 3, direct and indirect effects of greenness had opposite effects. When giving the direct effects, greenness exposure was associated with lower risk of hypertension (direct effect: $0.80,95 \% \mathrm{Cl}$ : $0.73-0.87$ for NDVI; $\mathrm{HR}=0.71,95 \% \mathrm{Cl}$ : $0.63-0.80$ for $\mathrm{EVI})$. However, the indirect effects of greenness exposure mediated through $\mathrm{PM}_{2.5}$ was related with increase risk of hypertension (indirect effect: $\mathrm{HR}=1.07,95 \% \mathrm{Cl}$ : $1.04-1.10$ for $\mathrm{NDVl} ; \mathrm{HR}=\mathrm{HR}=1.06,95 \% \mathrm{Cl}$ : 1.03-1.09 for EVI). There were $41.63 \%$ and $17.01 \%$ of its effects were mediated by $\mathrm{PM}_{2.5}$ for NDVI and EVI, respectively. We not observed significant mediation effects of BMI and leisure activity on the relationship between greenness and hypertension (Table S4).

\section{Discussion}

To our knowledge, this is the first prospective cohort study to examine the association between greenness exposure and hypertension incidence among the oldest-old population. The findings from our study showed the greatly protective effects of greenness exposure on hypertension incidence risk. Compared with the first tertile counterpart, the third tertile of NDVI value were associated with $49 \%$ lower hazard risks of hypertension incidence, respectively. Also for those participants at the highest tertile of EVI value, the risk of hypertension was reduced by $46 \%$. We observed that region had modification effects on the association between greenness exposure and hypertension. We have found significant mediation effects of air pollution exited on the association between greenness and hypertension. 
One of the highlights of our study was we observed the dose-response relationship between greenness and hypertension. As already discussed in past studies [20,34, 35], non-liner (dose-response) association between greenness exposure and health outcomes such as serum uric acid levels, physical function, and mortality have been detected in middle-aged or older adults, but same non-liner association between greenness and hypertension remains unclear. In our study, we found the threshold value of hypertension incidence in NDVI/EVI value were very small (Figure S2-S3), it suggested that an effort to expand residential greenness space was positive with declining in hypertension incidence risk. Namely, expanding greenness space may be a very highly cost effective approach for hypertension prevention for these oldest-old elderly. Whereas, due to limited evidence of greenness threshold for hypertension incidence in other population, the comparison between oldest-old and younger people need more study.

Our findings was supported by prior studies that demonstrated the protective effects of greenness exposure on hypertension incidence [36-38]. Although few of studies have been devoted to the oldest-old adults. In a earlier community-based cross-sectional study of participants aged 18 to 91 has shown that about $45 \%$ risk of hypertension was reduced due to greenness exposure among older adults over 65 years [16]. One observational survey looking at 5 counties in central China have found greenness exposure was associated with approximately $5 \%$ lower risk of hypertension in the middle-age and older population (mean age: 55.58) [7]. A sample that included 249,405 Medicare beneficiaries from Florida revealed a $13 \%$ risk decrease in hypertension attributed to greenness among adults older aged from 65 to 111 years [39]. However, a recent study from 33 communities of China indicated that greenness exposure seemed was a risk factor for hypertension in the elderly over 65 years (the proportion accounting for $9 \%$ of their sample) but no statistical significance was detected in this study [9].

Owing to the total number of the specific age elderly $(80+)$ was very limited, our national data incorporated large investigation complement study gaps existing in past literature with implications for illustrating the benefit of greenness on hypertension and deeper understanding the longevity. The determination that an association between greenness exposure and hypertension incidence is causal suggests improvement in residential greenness space may be helpful to supplement existing guidelines for the management of geriatric hypertension [40].

More importantly, the results of our study exhibited a greater protective effect of greenness exposure on hypertension incidence than prior published literature included older adults $[9,11,14,16]$, which indicated that the advantages of greenness for these oldest people were greater than expected. Our results provide new insights that the benefit of greenness exposure to hypertension prevention possible increases with age, especially for the oldest old people. Thus, it is of significant public health interest to expand capacious green space and offer accessible opportunity to green space in nursing home, geriatric hospital, and residence areas oldest-old gathered (e.g, longevity villages), may reduce specific age hypertension occurrence then prolong life-span.

Past studies proposed some explanations which may be part of the underlying mechanisms for the influence of greenness on hypertension, as following: 1) Exposure to greenness can alleviate emotional 
symptoms and pressure a person faced [41, 42]. 2) Greenness space offers accessible opportunities for physical activity and social interaction for the individual [20,43]. 3) The noise, air pollutants, and dust exposure can be offset in some extent by large greenness space [44]. Among them, weight control, physical activity, and reducing mental pressure were important prevention strategies involved in the current recommendations based on guidelines for the management of geratic hypertension. The current study also emphasized continues to update recommendations for the prevention of hypertension due to our advancing understanding of the environmental factors for hypertension incidence.

According to the results of subgroup analysis, we observed that modified effects were appeared in regions, residence, gender, and lifestyle, however, we found only a significant interaction effect of regions between greenness and hypertension. Oldest old population who living in Central/Western regions were be more vulnerable to greenness exposure than eastern regions (Figure 3). Generally, the greenness space reflects the level of social and economic development. As figure 2 presented, a relatively flourishing greenness covering distributed in eastern regions, which was confirmed by another study reported the greenness in China follows a pattern of south-high and north-low, east-high, and west-low [45]. Moreover, the urbanization rate was faster in the central and western regions than in the eastern and northeastern areas, rapidly urbanization consumed a number of open space and forest in central/western regions [46]. As scholars summarized that urbanization had a positive effect on eco-efficiency in the eastern China instead of central and western regions [47]. Hence, the findings support the policy decision that effective greenness space construction plan should be taken to deal with the risk of hypertension across regions especially central/western regions.

Recently, more and more studies paid attention to the underlying mediation effect of air pollutants on the association between greenness and hypertension/blood pressure but most of them were focusing on middle-aged or younger population and reported mixed study results involving partly, complete, and null mediation effects. A cross-sectional study enrolled over thirty thousand of middle-aged adults reported that air pollution partially mediated the relationships between residential greenness and DBP (mediation proportion was $21.6 \%$ ) [7]. In turn, Huang et al found air pollution completely mediated the influence of greenness on hypertension in 5,806 urban middle aged and elderly people [8]. In a study focusing on children and adolescents, the results showed not significant evidences for the potential mediation effect of air pollution on the greenness-BP association [15]. Similar to Jiang et al [7], we also found a partly mediation effects of air pollutant on the links between greenness and hypertension. And the proportion of mediation effect was higher than the study of Jiang et al, may be due to the more weaker body function the more easily the oldest old people was affected by air pollutants. It is well-known that forests, trees, and vegetation space are able to deal with unclean air environment through leaf stomata on the plant surface, then mitigating the health effects [48]. Therefore, implement practical air quality management and improve air quality still a effective measure to promote cardiovascular health, especially for China, which has more severe air environment and heavier air pollution related disease burden than western developed countries. 
Several limitations should be recognized. First, the individual precise residential address of the participant was not available due to privacy protection of the CLHLS. Under this condition, we used county/district level exposure information to reflect individual's exposure. Even though same method was applied in prior studies [49, 50], measurement error was exist to some extent although the units were set as random term in our analysis. But satellite data we used with high resolution, national-level representative sample enhanced the reliability and generalization of our findings. Also, previous published survey based on residential unit to examine the effects of exposure on health outcomes presented positive results, which was able to support the scientificity of our result [51-54]. Second, limited by the CLHLS project database, we could not collect information on greenness vegetation structure. That could not explain the estimation of the association between greenness areas and hypertension incidence varied by vegetation regions. Third, the baseline CLHLS project data lacked information on the measurement of physical activity (intensity and frequency). It was limited the generalization of our result to some extent. But it could be confirmed that the light-intensity physical activity pattern was dominated among the oldest-old population [55]. Fourth, it is not available to identify the exact event date of hypertension because a long interval between interviews which limited the ability to causal inference. However, the sensitivity analysis presented steady results (Table S3).

The strengths of our study provided evidence for the effects of greenness on hypertension among the elderly aged 80 and older basing on a prospective cohort design, large sample size, and 10-year follow-up, after controlling for various confounding variables. The study also underlined the importance of continued expansion for residential greenness space and promote the use of greens-pace especially in central/western regions. Furthermore, improve air quality also as a critical factor to reduce hypertension risk under the direct effect of greenness exposure.

Lastly, because the greenness is independent of conventional hypertension risk factors. We expect a comprehensive assessment included environmental factors of hypertension risk is needed to older adults. We also hope existing guideline for hypertension prevention expected to updated, then physicians can be aware of these environmental factors and inform their service objectives the potential risk management measures they can adopt.

\section{Conclusion}

Taken together, the current study provide representative sample of oldest-old population to indicate the protective effects of greenness exposure on hypertension incidence, prove a cause-and-effect link between greenness and hypertension incidence. Given the centrality of prevention to hypertension, we call for the government continuous to expand the coverage of greenness particularly in central/western regions. Implement more efforts to improve air quality also a vital approach to strengthen greenness benefit.

\section{Declarations}


Acknowledgements

The authors wish to thank participants of the CLHLS.

\section{Author's Contributions}

Wensu Zhou, Fenfen Zhou: Data cleaning; Wensu Zhou, Wenjuan Wan, Fenfen Zhou, Wen Chen, Li Ling: Conceptualization; Wensu Zhou, Wen Chen, Fenfen Zhou, Wenjuan Wang: Data curation, Writing, Original draft preparation, Methodology, Software, Reviewing; Wensu Zhou, Fenfen Zhou, Wen Chen, Li Ling: Visualization. Wensu Zhou, Fenfen Zhou, Wen Chen, Li Ling, Wenjuan Wang: Supervision.

\section{Funding}

The research is financially supported by National Natural Science Foundation of China (Grant No. U1911204, 51861125203), National Key R\&D Program of China (2017YFC0405900), the Project for Creative Research from Guangdong Water Resources Department (Grant No. 2018, 2020).

\section{Availability of data and materials}

The CLHLS is an open-publish database which can be downloaded at website http://cnsda.ruc.edu.cn/index.php?r=projects/view\&id=52572397.

\section{Ethics approval and consent to participate}

The Research Ethics Committees of Peking University and Duke University granted approval for the Protection of Human Subjects for the Chinese Longitudinal Healthy Longevity Survey, including collection of the data used for present study. The survey respondents gave informed consent before participation.

\section{Consent for publication}

Not applicable.

\section{Competing interests}

The authors declare that they have no competing interests.

\section{References}

1. Taylor L, Hochuli DF: Defining greenspace: Multiple uses across multiple disciplines. Landscape and Urban Planning 2017, 158:25-38.

2. Mills KT, Stefanescu A, He J: The global epidemiology of hypertension. Nat Rev Nephrol 2020, 16(4):223-237.

3. Dadvand P, Villanueva CM, Font-Ribera L, Martinez D, Basagana X, Belmonte J, Vrijheid M, Grazuleviciene R, Kogevinas M, Nieuwenhuijsen MJ: Risks and benefits of green spaces for children: 
a cross-sectional study of associations with sedentary behavior, obesity, asthma, and allergy. Environ Health Perspect 2014, 122(12):1329-1335.

4. Ageing and health [https://www.who.int/zh/news-room/fact-sheets/detail/ageing-and-health]

5. Kennedy BK, Berger SL, Brunet A, Campisi J, Cuervo AM, Epel ES, Franceschi C, Lithgow GJ, Morimoto RI, Pessin JE et al: Geroscience: linking aging to chronic disease. Cell 2014, 159(4):709713.

6. Stanaway JD, Afshin A, Gakidou E, Lim SS, Abate D, Abate KH, Abbafati C, Abbasi N, Abbastabar H, Abd-Allah $\mathrm{F}$ et al: Global, regional, and national comparative risk assessment of 84 behavioural, environmental and occupational, and metabolic risks or clusters of risks for 195 countries and territories, 1990-2017: a systematic analysis for the Global Burden of Disease Study 2017. The Lancet 2018, 392(10159):1923-1994.

7. Jiang J, Chen G, Li B, Li N, Liu F, Lu Y, Guo Y, Li S, Chen L, Xiang H: Associations of residential greenness with hypertension and blood pressure in a Chinese rural population: a cross-sectional study. Environ Sci Pollut Res Int 2021, 28(37):51693-51701.

8. Huang B, Xiao T, Grekousis G, Zhao H, He J, Dong G, Liu Y: Greenness-air pollution-physical activityhypertension association among middle-aged and older adults: Evidence from urban and rural China. Environ Res 2021, 195:110836.

9. Yang BY, Markevych I, Bloom MS, Heinrich J, Guo Y, Morawska L, Dharmage SC, Knibbs LD, Jalaludin $\mathrm{B}$, Jalava $\mathrm{P}$ et al: Community greenness, blood pressure, and hypertension in urban dwellers: The 33 Communities Chinese Health Study. Environ Int 2019, 126:727-734.

10. Dzhambov AM, Markevych I, Lercher P: Greenspace seems protective of both high and low blood pressure among residents of an Alpine valley. Environ Int 2018, 121(Pt 1):443-452.

11. Moreira TCL, Polizel JL, Santos IS, Filho DFS, Bensenor I, Lotufo PA, Mauad T: Green Spaces, Land Cover, Street Trees and Hypertension in the Megacity of Sao Paulo. Int J Environ Res Public Health 2020, 17(3).

12. Morita E, Naito M, Hishida A, Wakai K, Mori A, Asai Y, Okada R, Kawai S, Hamajima N: No association between the frequency of forest walking and blood pressure levels or the prevalence of hypertension in a cross-sectional study of a Japanese population. Environ Health Prev Med 2011, 16(5):299-306.

13. Zeng Y, Feng Q, Hesketh T, Christensen K, Vaupel JW: Survival, disabilities in activities of daily living, and physical and cognitive functioning among the oldest-old in China: a cohort study. The Lancet 2017, 389(10079):1619-1629.

14. Chen H, Burnett RT, Bai L, Kwong JC, Crouse DL, Lavigne E, Goldberg MS, Copes R, Benmarhnia T, Ilango SD et al: Residential Greenness and Cardiovascular Disease Incidence, Readmission, and Mortality. Environ Health Perspect 2020, 128(8):87005.

15. Luo YN, Yang BY, Zou Z, Markevych I, Browning M, Heinrich J, Bao WW, Guo Y, Hu LW, Chen G et al: Associations of greenness surrounding schools with blood pressure and hypertension: A nationwide cross-sectional study of 61,229 children and adolescents in China. Environ Res 2021, 204(Pt A):112004. 
16. Jia X, Yu Y, Xia W, Masri S, Sami M, Hu Z, Yu Z, Wu J: Cardiovascular diseases in middle aged and older adults in China: the joint effects and mediation of different types of physical exercise and neighborhood greenness and walkability. Environ Res 2018, 167:175-183.

17. Ochiai H, Ikei H, Song C, Kobayashi M, Takamatsu A, Miura T, Kagawa T, Li Q, Kumeda S, Imai M et al: Physiological and psychological effects of forest therapy on middle-aged males with high-normal blood pressure. Int J Environ Res Public Health 2015, 12(3):2532-2542.

18. Toda M, Den R, Hasegawa-Ohira M, Morimoto K: Effects of woodland walking on salivary stress markers cortisol and chromogranin A. Complement Ther Med 2013, 21(1):29-34.

19. Xie Y, He W, Zhang X, Cui J, Tian X, Chen J, Zhang K, Li S, Di N, Xiang H et al: Association of air pollution and greenness with carotid plaque: A prospective cohort study in China. Environ Pollut 2021, 273:116514.

20. Zhu A, Yan LL, Wu CD, James P, Zeng Y, Ji JS: Residential greenness, activities of daily living, and instrumental activities of daily living: A longitudinal cohort study of older adults in China. Environ Epidemiol 2019, 3(5):e065.

21. Zhu A, Yan L, Wu C, Ji JS: Residential Greenness and Frailty Among Older Adults: A Longitudinal Cohort in China. J Am Med Dir Assoc 2020, 21(6):759-765 e752.

22. Brook RD: The Environment and Blood Pressure. Cardiol Clin 2017, 35(2):213-221.

23. Zeng Y: Towards Deeper Research and Better Policy for Healthy Aging -Using the Unique Data of Chinese Longitudinal Healthy Longevity Survey. China Economic J 2012, 5(2-3):131-149.

24. Hu K, Keenan K, Hale JM, Börger T: The association between city-level air pollution and frailty among the elderly population in China. Health \& Place 2020, 64.

25. Lv Y, Zhou J, Kraus VB, Li T, Sarnat JA, Wang J, Liu Y, Chen H, Brasher MS, Mao C et al: Long-term exposure to PM2.5 and incidence of disability in activities of daily living among oldest old. Environ Pollut 2020, 259:113910.

26. Lv YB, Gao X, Yin ZX, Chen HS, Luo JS, Brasher MS, Kraus VB, Li TT, Zeng Y, Shi XM: Revisiting the association of blood pressure with mortality in oldest old people in China: community based, longitudinal prospective study. BMJ 2018, 361:k2158.

27. Lao XQ, Guo C, Chang LY, Bo Y, Zhang Z, Chuang YC, Jiang WK, Lin C, Tam T, Lau AKH et al: Longterm exposure to ambient fine particulate matter (PM2.5) and incident type 2 diabetes: a longitudinal cohort study. Diabetologia 2019, 62(5):759-769.

28. Katz S, Ford AB, Moskowitz RW, Jackson BA, Jaffe MW: STUDIES OF ILLNESS IN THE AGED. THE INDEX OF ADL: A STANDARDIZED MEASURE OF BIOLOGICAL AND PSYCHOSOCIAL FUNCTION. Jama 1963, 185:914-919.

29. Katz S, Downs TD, Cash HR, Grotz RC: Progress in development of the index of ADL. The Gerontologist 1970, 10(1):20-30.

30. van Donkelaar A, Hammer MS, Bindle L, Brauer M, Brook JR, Garay MJ, Hsu NC, Kalashnikova OV, Kahn RA, Lee $\mathrm{C}$ et al: Monthly Global Estimates of Fine Particulate Matter and Their Uncertainty. Environ Sci Technol 2021. 
31. Cao J, Qian D, Yang F: Socioeconomic disparities in leisure activities over the life course of the oldest-old in China. Australas J Ageing 2020, 39(3):e416-e424.

32. Huang YT, Yang HI: Causal Mediation Analysis of Survival Outcome with Multiple Mediators. Epidemiology 2017, 28(3):370-378.

33. Sanders AE, Akinkugbe AA, Fillingim RB, Ohrbach R, Greenspan JD, Maixner W, Bair E, Slade GD: Causal Mediation in the Development of Painful Temporomandibular Disorder. J Pain 2017, 18(4):428-436.

34. Ji JS, Zhu A, Lv Y, Shi X: Interaction between residential greenness and air pollution mortality: analysis of the Chinese Longitudinal Healthy Longevity Survey. The Lancet Planetary Health 2020, 4(3):e107-e115.

35. Dong X, Liu X, Zhang L, Li R, Tu R, Hou J, Mao Z, Huo W, Guo Y, Li S et al: Residential greenness associated with lower serum uric acid levels and hyperuricemia prevalence in a large Chinese rural population. Sci Total Environ 2021, 770:145300.

36. Markevych I, Thiering E, Fuertes E, Sugiri D, Berdel D, Koletzko S, von Berg A, Bauer CP, Heinrich J: A cross-sectional analysis of the effects of residential greenness on blood pressure in 10-year old children: results from the GINIplus and LISAplus studies. BMC Public Health 2014, 14:477.

37. Lee J, Tsunetsugu Y, Takayama N, Park BJ, Li Q, Song C, Komatsu M, Ikei H, Tyrvainen L, Kagawa T et al: Influence of forest therapy on cardiovascular relaxation in young adults. Evid Based Complement Alternat Med 2014, 2014:834360.

38. Li Q, Otsuka T, Kobayashi M, Wakayama Y, Inagaki H, Katsumata M, Hirata Y, Li Y, Hirata K, Shimizu T et al: Acute effects of walking in forest environments on cardiovascular and metabolic parameters. Eur J Appl Physiol 2011, 111(11):2845-2853.

39. Brown SC, Lombard J, Wang K, Byrne MM, Toro M, Plater-Zyberk E, Feaster DJ, Kardys J, Nardi MI, Perez-Gomez G et al: Neighborhood Greenness and Chronic Health Conditions in Medicare Beneficiaries. Am J Prev Med 2016, 51(1):78-89.

40. Society HBoCG, Diseases NCRCfGD-CAoGC: Chinese Guidelines for the Management of Hypertension in the Elderly (2019). Chinese Journal of Multiple Organ Diseases in the Elderly 2019, 18(2):81-106.

41. Sarkar C, Webster C, Gallacher J: Residential greenness and prevalence of major depressive disorders: a cross-sectional, observational, associational study of $94+\llbracket 879$ adult UK Biobank participants. The Lancet Planetary Health 2018, 2(4):e162-e173.

42. Tsunetsugu Y, Park BJ, Ishii H, Hirano H, Kagawa T, Miyazaki Y: Physiological effects of Shinrin-yoku (taking in the atmosphere of the forest) in an old-growth broadleaf forest in Yamagata Prefecture, Japan. J Physiol Anthropol 2007, 26(2):135-142.

43. Byambasukh $\mathrm{O}$, Snieder $\mathrm{H}$, Corpeleijn E: Relation Between Leisure Time, Commuting, and Occupational Physical Activity With Blood Pressure in 125402 Adults: The Lifelines Cohort. J Am Heart Assoc 2020, 9(4):e014313. 
44. Markevych I, Schoierer J, Hartig T, Chudnovsky A, Hystad P, Dzhambov AM, de Vries S, Triguero-Mas $M$, Brauer M, Nieuwenhuijsen MJ et al: Exploring pathways linking greenspace to health: Theoretical and methodological guidance. Environ Res 2017, 158:301-317.

45. Xu B, Pan J: Estimation of potential ecological carrying capacity in China. Environ Sci Pollut Res Int 2020, 27(15):18044-18063.

46. China's urbanization rate hits $60.6 \%$ [http://www.gov.cn/shuju/2019-08/16/content_5421576.htm]

47. Yue L, Xue D, Draz MU, Ahmad F, Li J, Shahzad F, Ali S: The Double-Edged Sword of Urbanization and Its Nexus with Eco-Efficiency in China. Int J Environ Res Public Health 2020, 17(2).

48. Chen L, Liu C, Zou R, Yang M, Zhang Z: Experimental examination of effectiveness of vegetation as bio-filter of particulate matters in the urban environment. Environ Pollut 2016, 208(Pt A):198-208.

49. Li G, Zhang H, Hu M, He J, Yang W, Zhao H, Zhu Z, Zhu J, Huang F: Associations of combined exposures to ambient temperature, air pollution, and green space with hypertension in rural areas of Anhui Province, China: A cross-sectional study. Environ Res 2021:112370.

50. Xue T, Zhu T, Zheng Y, Zhang Q: Declines in mental health associated with air pollution and temperature variability in China. Nat Commun 2019, 10(1):2165.

51. Lin H, Guo Y, Zheng Y, Di Q, Liu T, Xiao J, Li X, Zeng W, Cummings-Vaughn LA, Howard SW et al: Long-Term Effects of Ambient PM2.5 on Hypertension and Blood Pressure and Attributable Risk Among Older Chinese Adults. Hypertension 2017, 69(5):806-812.

52. Chen SY, Su TC, Lin YL, Chan CC: Short-term effects of air pollution on pulse pressure among nonsmoking adults. Epidemiology 2012, 23(2):341-348.

53. Di Q, Dai L, Wang Y, Zanobetti A, Choirat C, Schwartz JD, Dominici F: Association of Short-term Exposure to Air Pollution With Mortality in Older Adults. JAMA 2017, 318(24):2446-2456.

54. Zeng Y, Gu D, Purser J, Hoenig H, Christakis N: Associations of environmental factors with elderly health and mortality in China. Am J Public Health 2010, 100(2):298-305.

55. Li Y, Du X, Zhang C, Wang S: Physical activity among the elderly in China: a qualitative study. British journal of community nursing 2013, 18(7):340-342, 344, 346-348 passim.

\section{Figures}




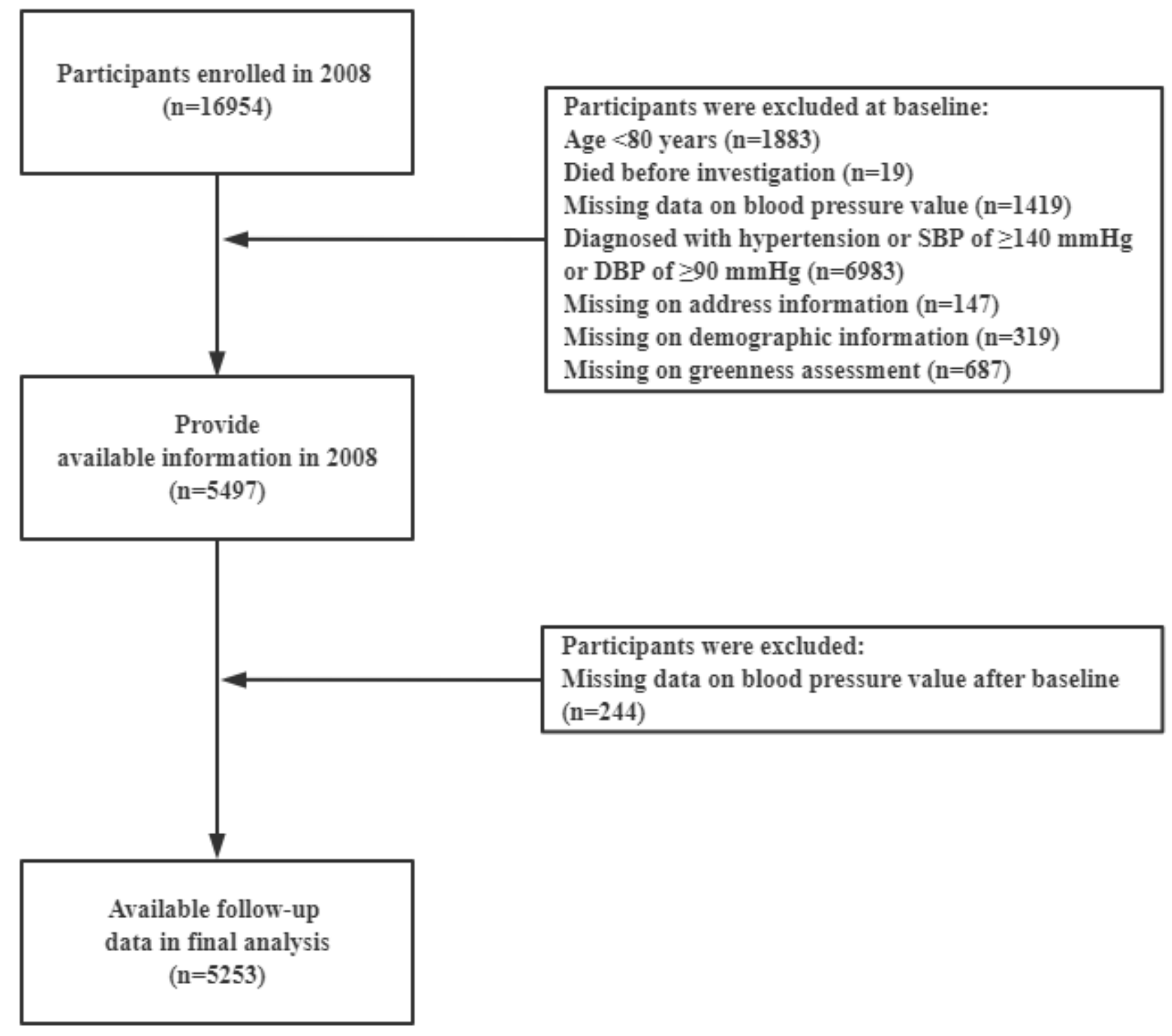

\section{Figure 1}

Flow diagram of study in group of people aged $80+$

\section{Figure 2}

The NDVI/EVI value of in 652 units of 23 provinces in China at baseline for 5253 participants 


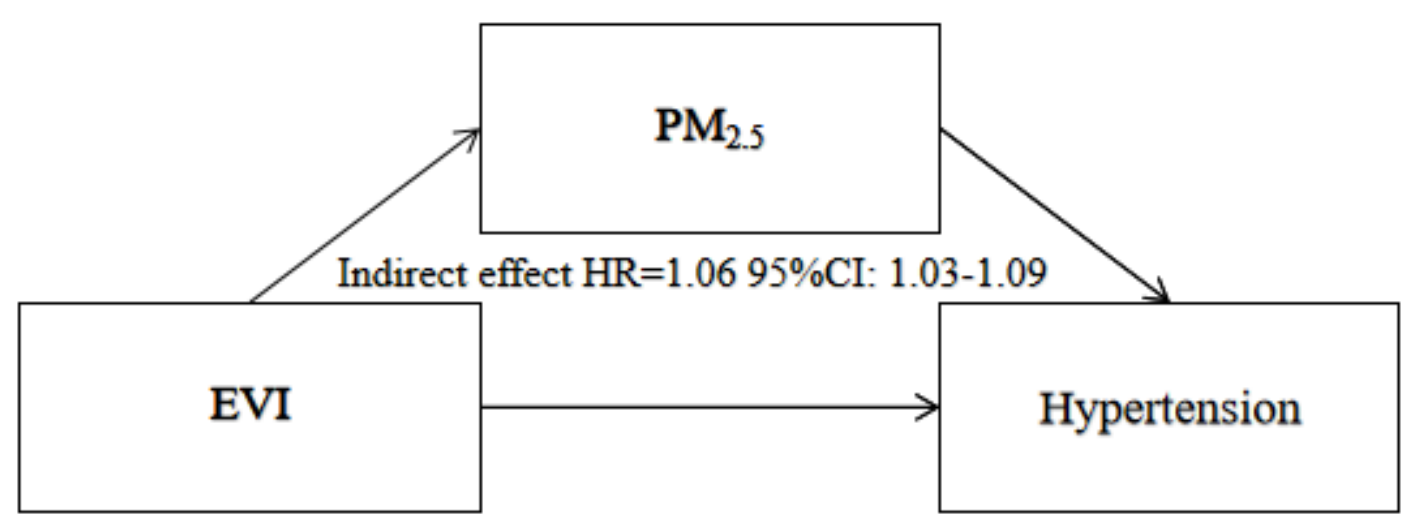

Direct effect $\mathrm{HR}=0.67,95 \% \mathrm{CI}: 0.59-0.76$

Total effect HR=0.71, $95 \% \mathrm{CI}: 0.63-0.80$

The mediation proportion was $17.01 \%$

B

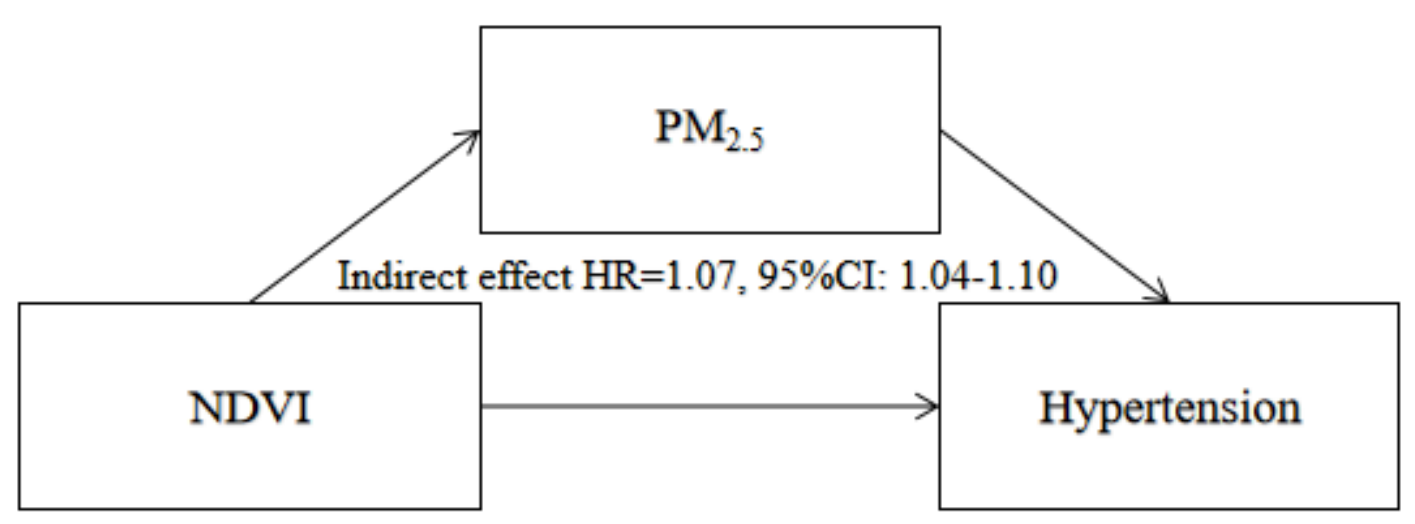

Direct effect $\mathrm{HR}=0.80,95 \% \mathrm{CI}: 0.73-0.87$

Total effect HR=0.85, 95\%CI: $0.78-0.92$

The mediation proportion was $41.63 \%$

Figure 3

(A) The association of EVI and hypertension mediated by $\mathrm{PM}_{2.5}$. $(\mathrm{B})$ The association of NDVI and hypertension mediated by $\mathrm{PM}_{2.5}$. All of analysis was adjusted for age, living arrangement, regions, $A D L$, residence, gender, smoking, drinking, exercising, pension, martial status, education attainment, selfreported diabetes, and self-reported heart disease.

\section{Supplementary Files}

This is a list of supplementary files associated with this preprint. Click to download. 
- Supplementmaterials.docx

Page 26/26 